\title{
Factors Affecting Rapid Turnover of Novice Nurses in University Hospitals
}

\author{
Eiko Suzuki ${ }^{1,2}$, Ichiro Itomine ${ }^{3}$, Yuka Kanoya ${ }^{4}$, Takeshi Katsuki ${ }^{5}$, Sayaka HoriI ${ }^{1}$ and \\ Chifumi SATO ${ }^{2}$
}

${ }^{1}$ Department of Nursing, Tenshi College, ${ }^{2}$ Department of Analytical Health Science, Graduate School of Health Sciences, Tokyo Medical and Dental University, ${ }^{3}$ Department of Nursing of Ibaraki Prefectural University of Health Sciences, ${ }^{4}$ Course of Community Health Nursing, School of Nursing, Yamagata University and ${ }^{5}$ Department of Nursing of Jobu Univercity, Japan

\begin{abstract}
Factors Affecting Rapid Turnover of Novice Nurses in University Hospitals: Eiko Suzuki, et al. Department of Analytical Health Science, Graduate School of Health Sciences, Tokyo Medical and Dental University-Rapid turnover of novice nurses eventually results in a shortage of veteran nurses. This study aimed to clarify the factors affecting rapid turnover of novice nurses in a prospective manner. We carried out an investigation in 20 university hospitals whose directors of nursing service departments accepted our request to cooperate with our research program. These hospitals were selected from all of the 102 university hospitals listed in The Hospital Catalog of Japan. The subjects were 1,203 novice hospital nurses who gave their informed consent for participation in our study. The questionnaires, which dealt with burnout, assertiveness, stressful life events, reality shock, ward assignment preference, transfer preference, job satisfaction (workplace, salary, workload, and overtime), social support and coping mechanisms were completed by 923 novice nurses in June 2003. Then, their turnover was investigated in December 2003. Thirty-seven novice nurses (4.0\%) quit during this period. Multiple logistic regression analysis showed that the factors affecting rapid turnover were 1) graduation from vocational nursing schools, 2) dissatisfaction with assignment to a ward contrary to their desire, and 3) no peers for support. Assignment of novice nurses to wards they choose as far as possible, avoidance of assigning novice nurses to wards alone, and establishment of a support system for nurses who graduate from vocational nursing
\end{abstract}

Received Jul 19, 2005; Accepted Nov 16, 2005

Correspondence to: E. Suzuki, Department of Analytical Health Science, Graduate School of Health Sciences, Tokyo Medical and Dental University, 1-30, Kita 13, Higashi 3, Higashi-ku, Sapporo 065-0013,Japan (e-mail: chihiroeiko@hotmail.com) schools seem to be important for preventing rapid turnover of novice nurses.

(J Occup Health 2006; 48: 49-61)

Key words: Novice nurses, Rapid turnover, Risk factor, Social support, Longitudinal study, Burnout, University hospital

Rapid turnover of novice nurses eventually leads to a lack of veteran nurses who form the backbone of nursing, giving rise to a vicious cycle of inadequate support and supervision for novice nurses, resulting in further resignation of novice nurses. Consequently, it is hard to expect that enough nurses with the skills needed to meet today's highly advanced medical standards will be educated. While the turnover of nurses with long careers ${ }^{1)}$ and the factors affecting it have been investigated ${ }^{2-4)}$, only a few studies on novice nurses have been conducted ${ }^{5}$.

It has been reported that novice nurses find it hard to form an accurate perspective of their profession and to obtain job satisfaction ${ }^{6-8)}$. Therefore, the process of acquiring the specialized skills of nursing is recognized to be valuable for novice nurses. Moreover, the importance of support for them during this period has been pointed out ${ }^{5,7,9)}$. However, the factors affecting the rapid turnover of novice nurses, in particular, the turnover within one year have not been investigated systematically.

The following four factors are reported to be causes of turnover among nurses with long careers: (1) burnout ${ }^{10)}$, (2) factors related to their workplace (office satisfaction and interpersonal relationships, etc. $)^{2,4,11-13)}$, (3) factors related to their life cycles ${ }^{2,11,12)}$, and (4) factors related to their individual characteristics ${ }^{4)}$. However, (2), (3), and (4) are assumed to be causes of burnout ${ }^{14-17)}$. It is supposed that these factors form a complex and influence each other. 
Leiter and Maslach ${ }^{18)}$ constructed a burnout process model. They reported the following processes. A lack of coping ability and social support with an increasing workload and conflicts due to personal problems tend to cause tiredness. The tiredness causes cynicism, which then causes burnout. As a result, decreasing commitment to co-workers causes the problems of resignation and leave-taking, etc. ${ }^{10)}$

University hospitals employ the greatest number of novice nurses, provide educational and group training programs for them and have uniform nursing educational standards. However, the turnover rate is higher than for hospitals of other organizations ${ }^{1)}$. In fact, university hospitals face continuous nursing shortages. Hence, it is important to clarify the factors affecting the rapid turnover of novice nurses and to establish an effective support system.

Therefore, we examined the relations between burnout of novice nurses and various factors that have been reported to be connected to it, in some recent investigations on novice nurses, by a cross-sectional study. In the result, the following were enumerated as factors with strong relations to burnout: family sickness and severe personal illness in the last year, reality shock, assignment satisfaction, clinical area, job satisfaction, salary satisfaction, workload, overtime work, hope for job change, social support (colleagues, senior nurses, friends and family members) and assertiveness.

In this study, based on those results, we aimed to clarify whether those factors caused rapid turnover of novice nurses in university hospitals, and whether burnout affected factors related to the rapid turnover of novice nurses.

\section{Subjects and Methods}

This study used a longitudinal design. Of the university hospitals (excluding psychiatric hospitals) listed in the 2001-2002 Hospital Catalog of Japan ${ }^{19)}$, all of the 102 hospitals with more than 400 beds were enrolled. The primary survey was conducted by mailing a questionnaire with return postage to the director of the nursing service department in each hospital to ascertain the employment and educational status of novice nurses. Valid responses were obtained from 41 directors, with 20 agreeing to participate in a further study. The subjects of this study were 1,203 novice full-time nurses (nurses, public health nurses, and midwives) who commenced their nursing careers in one of the 20 hospitals in 2003. In June 2003, a self-administered questionnaire was mailed to each nurse, who was asked to return the completed form anonymously to the designated box installed in each hospital. Those who returned valid responses were followed until December 2003. Retirement of novice nurses was confirmed by their birthdays, which were provided by the director of the nursing service department in each hospital.

The results of the primary survey clarified that all university hospitals assigned preceptors to novice nurses and provided group training led by the director of nursing education. No marked differences were apparent in the amount of group training or the timing of commencing night shift work for the novice nurses between the 20 participating hospitals and the other non-participating institutions.

\section{Nurse attributes}

Information was collected on gender, birthday, final academic background (vocational nursing school, nursing college, nursing university, college or university degree other than nursing), marital status, children, living arrangements, specialization (general nursing, public health or maternity), the location of the hospital, the arrangement of nursing (ratio of patients per nurse), and the ward assignment.

\section{Burnout}

We used the Japanese version of the Maslach Burnout Inventory (MBI). The original scale, developed by Maslach and Jackson in 1981 ${ }^{20)}$, assesses the intensity and frequency of 25 items and consists of three subscales: 1) physical exhaustion, 2) emotional exhaustion and depersonalization, and 3) personal accomplishment. The higher the score for subscales 1 ) or 2) is, the greater the burnout; while the lower the score for subscale 3 ) is, the greater the burnout. The Japanese version was described and verified for its reliability and validity by Higashiguchi et al. in $1998^{21)}$. $\mathrm{We}^{22)}$ have already assessed the reliability and practicality of rating the frequency of 22 of the 25 items. This study, therefore, followed this format. In accordance with Higashiguchi et al. ${ }^{21)}$, three factors were extracted by factor analysis in this study, and Cronbach's alpha coefficients ranged from .77 to .80 . Grading frequencies of seven scores from 0 to 6 points and dividing the total score by the number of questions determined the score for each subscale. In addition, the total MBI score proposed by Lewiston et al. ${ }^{23)}$ was calculated: (mean score of physical exhaustion + mean score of depersonalization/emotional exhaustion-mean score of personal accomplishment +10 ). The higher the total score is the greater the burnout. Scores ranged from 0-6 for physical exhaustion, 0-8 for depersonalization/ emotional exhaustion, and personal accomplishment, and from 2 (least burnout) to 32 (most burnout) for the total MBI score. Permission to use the MBI was obtained from Consulting Psychologists Press Inc. (2003, approval number 14447).

\section{Assertiveness}

We used the Japanese version of the Rathus Assertiveness Schedule (RAS), which was described and 
verified for reliability and validity by Suzuki et al. ${ }^{24,25)}$ in 2004. The original scale was developed by Rathus ${ }^{26)}$ in 1973, and consists of 30 questions. Higher RAS scores indicate greater degrees of assertiveness. As was the case with the original version, factor analysis in this study extracted eight factors, and Cronbach's alpha coefficient was .83. The scale ranges from -90 (least assertive) to +90 (most assertive). Permission to use the RAS was obtained from the Association for Advancement of Behavior Therapy (2002).

\section{Stressful life events}

Holmes and Rahe ${ }^{27)}$ made a checklist called the "Social Readjustment Ration Scale (SRRS)" based on the premise that good or bad events in one's life can increase stress levels and make one more susceptible to illness and mental health problems. We referred to the high-ranking items in the SRRS to examine whether subjects had experienced serious illness of a family member, serious personal illness, the death of a close friend, or death of a family member within the previous twelve months.

\section{Reality shock, ward assignment preference and transfer preference}

Based on the definition of reality shock by $\operatorname{Kramer}^{28)}$, to ascertain reality shock, each subject was asked to answer the question "Are you shocked at the difference between what you learned at school and what you are actually doing at work?" with options of "always", "occasionally", "hardly ever" or "never". As to ward assignment preference, each subject was asked to answer "Were you assigned to a ward of your choice?" with options of "satisfied to be assigned to the ward of choice", "satisfied despite being assigned to a different ward", or "dissatisfied about being assigned to a different ward". In terms of transfer preference, each subject was asked to answer, "Do you want to change your career path?" with options of: "no", "want to get a higher degree", "want to change workplace" or "want to find another career".

\section{Job satisfaction (workplace, salary, workload, and overtime)}

As to the workplace, each subject was asked to answer, "Are you satisfied with your workplace?" with options of "very satisfied", "largely satisfied", "slightly dissatisfied" or "very dissatisfied". For salary, each subject was asked to answer, "Are you satisfied with your salary?" with options of "very satisfied", "largely satisfied", "slightly dissatisfied" or "very dissatisfied". In terms of workload, each subject was asked to answer, "How would you describe your workload?" with options of "very high", "slightly high", "slightly low" or "very low". The amount of overtime per week was classified into "no overtime", "1-3 h", "4-6 h", "7-9 h" and "10 h or more".

\section{Social support, coping mechanisms}

With regard to social support, each subject was asked whether or not he or she had any person to talk to about concerns or problems on the job. Each subject was asked to identify individuals with whom he or she could talk about these issues among the following: "any person", "peers", "senior nursing staff", "boss", and "friends and family members".

Questions about coping mechanisms were prepared based on the coping taxonomy developed by Pine and Kafry ${ }^{29)}$. Each subject was asked "When you experience difficulties, concerns or problems at the workplace, which of the following four actions would you most likely take?" with options of "talk things over with the parties involved", "change my own behavior and actions that caused the problem", "immerse myself in things not related to the problem", or "depend on alcohol or drugs".

\section{Ethical considerations}

Participation of the directors of the nursing service department at each hospital was requested after explaining the purpose of this study orally and in writing. The study objectives and procedures were explained to the participating nurses in writing; they were informed that their anonymity would be guaranteed, that their participation and withdrawal would be of their own free will, and that refusal to participate or withdrawing consent would not result in any negative consequences. We stated that the study protocol would strictly follow the Declaration of Helsinki and the basic ethical guidelines for epidemiological studies as established by the Ministry of Education, Culture, Sports, Science and Technology, of Japan. The protocol of this study was approved by the ethics review committee of Tokyo Medical and Dental University.

\section{Statistical analysis}

The subjects were divided into a retired group and nonretired group in December 2003. We calculated the mean value of the total MBI score and the assertiveness score of each group investigated in June 2003 and the results were compared. One-way ANOVA was used to assess significant differences between mean values. Based on the presence/absence and frequency of the factors affecting turnover in June 2003, risk ratios and 95\% confidence intervals were calculated. Of the variables with significant risk ratios, i.e., gender, age and burnout scores, multiple logistic analysis was conducted by using the total MBI score and physical exhaustion as explanatory variables, and turnover as an objective variable. Variables were selected by the stepwise method. Total MBI scores and physical scores were treated as continuous variables. Risk ratios and $95 \%$ confidence intervals were calculated in vocational nursing school 
Table 1. Nurse attributes and clinical departments with respect to rapid turnover

\begin{tabular}{|c|c|c|c|c|}
\hline & & Quit & Not quit & Total \\
\hline & Nurs & $\operatorname{ses}(n=37)$ & Nurses $(n=886)$ & $\mathrm{n}=923$ \\
\hline Average age & 22.8 & & 22.8 & 22.8 \\
\hline \multicolumn{5}{|l|}{ Highest educational level } \\
\hline Vocational school & 32 & $(86.5)$ & $485(54.7)$ & $517(56.0) * *$ \\
\hline Nursing college & 3 & $(8.1)$ & $200(22.6)$ & $203(22.0)$ \\
\hline Nursing university & 1 & $(2.7)$ & $176(19.9)$ & $177(19.2)$ \\
\hline $\begin{array}{l}\text { Graduated from college or university } \\
\text { with a degree other than nursing }\end{array}$ & 0 & & $22 \quad(2.5)$ & $22 \quad(2.4)$ \\
\hline Unknown & 1 & $(2.7)$ & $3 \quad(0.34)$ & $4 \quad(0.4)$ \\
\hline \multicolumn{5}{|l|}{ Department } \\
\hline Outpatient & 2 & (5.4) & $24 \quad(2.7)$ & $26 \quad(2.8) * *$ \\
\hline Obstetrics and gynecology & 2 & (5.4) & $33 \quad(3.7)$ & $35 \quad(3.8)$ \\
\hline Psychiatry & 0 & & $14 \quad(1.6)$ & $14 \quad(1.5)$ \\
\hline Mixed ward & 7 & $(18.9)$ & $103(11.6)$ & $110(11.9)$ \\
\hline Pediatrics & 2 & $(5.4)$ & $48 \quad(5.4)$ & $50 \quad(5.4)$ \\
\hline Operating room & 1 & (2.7) & $60 \quad(6.8)$ & $61 \quad(6.6)$ \\
\hline Critical care (CCU/ICU/TTC/NICU) & 3 & $(8.1)$ & $95(10.7)$ & $98(10.6)$ \\
\hline Internal medicine & 9 & $(24.3)$ & $197(22.2)$ & $206(22.3)$ \\
\hline Surgery & 8 & $(21.6)$ & $253(28.6)$ & $261(28.3)$ \\
\hline Others & 1 & $(2.7)$ & $52 \quad(5.9)$ & $53 \quad(5.7)$ \\
\hline Unknown & 2 & (5.4) & $7 \quad(0.8)$ & $9 \quad(1.0)$ \\
\hline
\end{tabular}

Figures in parentheses indicate percentages.

$* *: p<0.01$

graduates based on the presence/absence and frequency of the factors affecting turnover in June 2003, in which variables were selected by the stepwise method. In addition, the characteristics of the novice nurses without support from peers were examined. SAS version 8.2 was used for the analysis.

\section{Results}

\section{Subject attributes}

In June 2003, responses were obtained from 1,030 nurses $(85.6 \%)$. Response rates varied among the participating hospitals: $34 \%$ in one hospital, $50 \%$ in another and $60-100 \%$ in the remaining 18 . There were no responses from public health nurses, and 25 midwives were excluded. Further more, 17 nurses who were married or had children were excluded because social backgrounds and daily lives are different from single nurses, married nurses and parents. The subjects of the analysis were 988 novice nurses. Valid responses to gender, age, MBI, and RAS questions were obtained from 923 nurses (93.4\%, 890 females and 33 males), and these nurses were then followed. By December 2003, 37 of the 923 nurses had quit (4.0\%, 36 females and one male). Table 1 shows nurse attributes and clinical departments with respect to rapid turnover. The average ages $( \pm$ standard deviation, SD) were $22.8( \pm 3.2)$ yr for nurses who quit, $22.8( \pm 1.9)$ yr for those who did not, with no significant difference between the two groups.

The proportion of vocational school graduates (approximately 90\%) among the nurses who quit was significantly greater than that of the nurses with other final academic backgrounds. Table 2 shows average burnout and assertiveness scores with respect to rapid turnover. Among the total subject population, the average total MBI score $( \pm \mathrm{SD})$ was $12.2( \pm 2.3)$, average physical exhaustion score, $3.7( \pm 1.1)$, average emotional exhaustion/depersonalization score, $1.5( \pm 1.1)$, average personal accomplishment score, $3.0( \pm 1.1)$, and average assertiveness score $( \pm \mathrm{SD}),-12.4( \pm 20.8)$. There were no significant differences among the participating hospitals for average scores on burnout subscales or the average assertiveness score, and rate of quitting.

Factors affecting rapid turnover among all subjects

ANOVA revealed that nurses who had quit had significantly higher scores for total MBI and physical exhaustion than those who did not $(p<.05$ and $p<.01$, respectively). Total MBI and physical exhaustion scores were significantly higher for nurses who quit, than for nurses who did not quit $(p<.01)$. 
Table 2. Burnout and assertiveness scores with respect to turnover and average, maximum and minimum of total subjects

\begin{tabular}{lrrrrr}
\hline & Quit & Not quit & \multicolumn{2}{c}{ Total subjects $(\mathrm{n}=923)$} \\
\hline & Nurses $(\mathrm{n}=37)$ & Nurses $(\mathrm{n}=886)$ & Mean $\pm \mathrm{SD}$ & Maximum & Minimum \\
\hline Burnout & & & & & \\
$\quad$ Total MBI score & $13.0 \pm 2.1$ & $12.1 \pm 2.3 * *$ & $12.2 \pm 2.3$ & 19.8 & 6.0 \\
$\quad$ Physical exhaustion & $4.2 \pm 1.0$ & $3.7 \pm 1.1 * *$ & $3.7 \pm 1.1$ & 6.0 & 0.2 \\
$\quad$ Emotional exhaustion & $1.6 \pm 1.2$ & $1.5 \pm 1.1$ & $1.5 \pm 1.1$ & 5.5 & 0 \\
$\quad$ and depersonalization & & & & 5.6 & 0 \\
$\quad \begin{array}{l}\text { Personal accomplishment } \\
\text { Assertiveness }\end{array}$ & $2.9 \pm 0.8$ & $3.0 \pm 1.1$ & $3.0 \pm 1.1$ & 60 & -71 \\
\hline
\end{tabular}

$* *: p<0.01$

Table 3. Risk ratios and $95 \%$ confidence intervals for rapid turnover among novice nurses (Nurse attributes)

$(\%)$

\begin{tabular}{|c|c|c|c|c|c|}
\hline Gender & Frequency & \multicolumn{2}{|l|}{ Quit } & Risk ratio & $95 \% \mathrm{CI}$ \\
\hline female & 890 & 36 & $(4.0)$ & 1.00 & \\
\hline male & 33 & 1 & $(3.0)$ & 0.75 & $0.11-5.30$ \\
\hline \multicolumn{6}{|l|}{ Age } \\
\hline$\geq 24 \mathrm{yr}$ & 172 & 7 & $(4.1)$ & 1.00 & \\
\hline$<24 \mathrm{yr}$ & 751 & 30 & $(4.0)$ & 0.98 & $0.44-2.20$ \\
\hline \multicolumn{6}{|l|}{ Highest educational level } \\
\hline University of nursing & 177 & 1 & $(0.6)$ & 1.00 & \\
\hline College or university degree other than nursing & 22 & 0 & $(0.0)$ & 2.58 & $0.11-61.48$ \\
\hline College of nursing & 203 & 3 & $(1.5)$ & 2.62 & $0.27-24.92$ \\
\hline Vocational school of nursing & 517 & 32 & $(6.2)$ & 10.96 & $1.51-79.59 * *$ \\
\hline \multicolumn{6}{|l|}{ Living arrangements } \\
\hline Living with family or inmate & 221 & 10 & $(4.5)$ & 1.00 & \\
\hline Living alone & 700 & 26 & $(3.7)$ & 0.82 & $0.40-1.68$ \\
\hline \multicolumn{6}{|l|}{ Location of the hospital } \\
\hline in Tokyo & 426 & 14 & $(3.3)$ & 1.00 & \\
\hline in other area & 497 & 23 & (4.6) & 1.41 & $0.73-2.70$ \\
\hline \multicolumn{6}{|l|}{ Nursing arrangement (ratio of patients per nurses) } \\
\hline $2.5: 1$ & 100 & 4 & $(4.0)$ & 1.00 & \\
\hline $2: 1$ & 823 & 33 & $(4.0)$ & 1.00 & $0.36-2.76$ \\
\hline \multicolumn{6}{|l|}{ Ward } \\
\hline Outpatient & 26 & 2 & (7.7) & 1.00 & \\
\hline Other & 888 & 33 & (3.7) & 0.48 & $0.12-1.91$ \\
\hline \multicolumn{6}{|l|}{ Department } \\
\hline Mixed ward & 110 & 7 & $(6.4)$ & 1.00 & \\
\hline Obstetrics and gynecology & 35 & 2 & $(5.7)$ & 0.90 & $0.20-4.13$ \\
\hline Psychiatry & 14 & 0 & $(0.0)$ & 0.49 & $0.03-8.21$ \\
\hline Pediatrics & 50 & 2 & $(4.0)$ & 0.63 & $0.14-2.92$ \\
\hline Operating room & 61 & 1 & $(1.6)$ & 0.26 & $0.03-2.05$ \\
\hline Critical care (CCU/ICU/TTC/NICU) & 98 & 3 & $(3.1)$ & 0.48 & $0.13-1.81$ \\
\hline Internal medicine & 206 & 9 & (4.4) & 0.69 & $0.26-1.79$ \\
\hline Surgery & 261 & 8 & $(3.1)$ & 0.48 & $0.18-1.30$ \\
\hline Others & 53 & 1 & (1.9) & 0.30 & $0.04-2.35$ \\
\hline
\end{tabular}

**: $p<0.01$ 
Table 4. Risk ratios and $95 \%$ confidence intervals for rapid turnover among novice nurses (Stressful life events, reality shock, ward assignment preference, transfer preference, job satisfaction [workplace, salary, workload, and overtime])

\begin{tabular}{|c|c|c|c|c|c|}
\hline \multirow{2}{*}{ Stressful life events } & \multirow[t]{2}{*}{ Frequency } & \multicolumn{2}{|l|}{ Quit } & \multirow[t]{2}{*}{ Risk ratio } & $95 \% \mathrm{CI}$ \\
\hline \multirow{2}{*}{\multicolumn{6}{|c|}{ Your family member had serious illness }} \\
\hline & & & & & \\
\hline No & 840 & 31 & (3.7) & 1.00 & \\
\hline Yes & 83 & 6 & $(7.2)$ & 1.96 & $0.84-4.56$ \\
\hline \multicolumn{6}{|l|}{ You had serious illness } \\
\hline No & 911 & 37 & $(4.1)$ & 1.00 & \\
\hline Yes & 12 & 0 & $(0.0)$ & 0.94 & $0.06-14.43$ \\
\hline \multicolumn{6}{|l|}{ You lost a close friend } \\
\hline No & 878 & 34 & (3.9) & 1.00 & \\
\hline Yes & 45 & 3 & (6.7) & 1.72 & $0.55-5.39$ \\
\hline \multicolumn{6}{|l|}{ You lost a family member } \\
\hline No & 866 & 33 & $(3.8)$ & 1.00 & \\
\hline Yes & 57 & 4 & $(7.0)$ & 1.84 & $0.68-5.02$ \\
\hline \multicolumn{6}{|l|}{ Reality shock } \\
\hline Never (frequency $=1$ ) or Hardly ever & 83 & 0 & $(0.0)$ & 1.00 & \\
\hline Occasionally & 595 & 26 & (4.4) & 7.47 & $0.46-121.43$ \\
\hline Always & 242 & 11 & (4.6) & 7.95 & $0.47-133.46$ \\
\hline \multicolumn{6}{|l|}{ Ward assignment preference } \\
\hline Satisfied ( the ward desired) & 441 & 14 & (3.2) & 1.00 & \\
\hline Satisfied (the ward not desired) & 329 & 9 & (2.7) & 0.86 & $0.38-1.97$ \\
\hline Dissatisfied (the ward not desired) & 139 & 13 & $(9.4)$ & 2.95 & $1.42-6.12 * *$ \\
\hline \multicolumn{6}{|l|}{ Transfer preference } \\
\hline No & 524 & 12 & (2.3) & 1.00 & \\
\hline Want to get higher degree & 116 & 6 & $(5.2)$ & 2.26 & $0.87-5.89$ \\
\hline Want to change workplace & 179 & 12 & (6.7) & 2.93 & $1.34-6.40 * *$ \\
\hline Want to find another career & 94 & 6 & (6.4) & 2.79 & $1.07-7.24 *$ \\
\hline \multicolumn{6}{|l|}{ Workplace } \\
\hline Very satisfied & 141 & 2 & (1.4) & 1.00 & \\
\hline Largely satisfied & 527 & 15 & (2.9) & 2.01 & $0.46-8.67$ \\
\hline Slightly dissatisfied & 205 & 15 & $(7.3)$ & 5.16 & $1.20-22.21 *$ \\
\hline Very dissatisfied & 48 & 5 & $(10.4)$ & 7.34 & $1.47-36.62 * *$ \\
\hline \multicolumn{6}{|l|}{ Salary } \\
\hline Very satisfied & 117 & 7 & $(6.0)$ & 1.00 & \\
\hline Largely satisfied & 445 & 15 & (3.4) & 0.56 & $0.24-1.35$ \\
\hline Slightly dissatisfied & 289 & 12 & $(4.2)$ & 0.69 & $0.28-1.72$ \\
\hline Very dissatisfied & 70 & 3 & (4.3) & 0.72 & $0.19-2.68$ \\
\hline \multicolumn{6}{|l|}{ Workload } \\
\hline Very low(frequency $=1)$ or slightly low & 49 & 3 & $(6.1)$ & 1.00 & \\
\hline Slightly high & 601 & 25 & $(4.2)$ & 0.68 & $0.21-2.17$ \\
\hline Very high & 260 & 9 & (3.5) & 0.57 & $0.16-2.01$ \\
\hline \multicolumn{6}{|l|}{ Overtime } \\
\hline No overtime & 63 & 2 & (3.2) & 1.00 & \\
\hline $1-3 \mathrm{~h}$ & 226 & 11 & (4.9) & 1.53 & $0.35-6.74$ \\
\hline $4-6 \mathrm{~h}$ & 166 & 6 & (3.6) & 1.14 & $0.24-5.49$ \\
\hline $7-9 \mathrm{~h}$ & 160 & 9 & (5.6) & 1.77 & $0.39-7.97$ \\
\hline $10 \mathrm{~h}$ or more & 292 & 9 & (3.1) & 0.97 & $0.22-4.39$ \\
\hline
\end{tabular}

$*: p<0.05, * *: p<0.01$ 
Table 5. Risk ratios and $95 \%$ confidence intervals for rapid turnover among novice nurses (Social support, coping mechanisms)

\begin{tabular}{|c|c|c|c|c|c|}
\hline & Frequency & \multicolumn{2}{|c|}{ Quit } & Risk ratio & $95 \% \mathrm{CI}$ \\
\hline \multicolumn{6}{|l|}{ Support from peers } \\
\hline Yes & 722 & 22 & $(3.1)$ & 1.00 & \\
\hline No & 201 & 15 & (7.5) & 2.45 & $1.29-4.63 * *$ \\
\hline \multicolumn{6}{|l|}{ Support from senior nursing staff } \\
\hline Yes & 296 & 9 & $(3.0)$ & 1.00 & \\
\hline No & 627 & 28 & (4.5) & 1.47 & $0.70-3.07$ \\
\hline \multicolumn{6}{|l|}{ Support from boss } \\
\hline Yes & 59 & 2 & (3.4) & 1.00 & \\
\hline No & 864 & 35 & $(4.1)$ & 1.20 & $0.29-4.85$ \\
\hline \multicolumn{6}{|l|}{ Support from friends and family members } \\
\hline Yes & 768 & 32 & $(4.2)$ & 1.00 & \\
\hline No & 155 & 5 & $(3.2)$ & 0.77 & $0.31-1.96$ \\
\hline \multicolumn{6}{|l|}{ Social support any of above persons } \\
\hline Yes & 884 & 34 & (3.9) & 1.00 & \\
\hline No & 39 & 3 & $(7.7)$ & 2.00 & $0.64-6.23$ \\
\hline \multicolumn{6}{|l|}{ Coping } \\
\hline Talk things over with the parties involved & 143 & 6 & $(4.2)$ & 1.00 & \\
\hline $\begin{array}{l}\text { Change my own behavior and actions } \\
\text { that caused the problem }\end{array}$ & 534 & 20 & $(3.8)$ & 0.89 & $0.37-2.18$ \\
\hline Immerse myself in things not related to the problem & m 205 & 10 & $(4.9)$ & 1.16 & $0.43-3.13$ \\
\hline Depend on alcohol or drugs & 39 & 1 & $(2.6)$ & 0.61 & $0.08-4.93$ \\
\hline
\end{tabular}

$* *: p<0.01$

Tables 3, 4 and 5 show the rapid turnover, risk ratios, and $95 \%$ confidence intervals, respectively. The risk ratio of nurses who graduated from vocational nursing schools to those who graduated from nursing universities was $10.96(p<.01)$. No significant differences were apparent between these two groups with respect to gender, age, living arrangements, hospital location, ward assignment or department, and the arrangement of nursing (ratio of patients per nurse).

None of the nurses who reported having experienced serious illness over the last twelve months quit, and there were no significant differences in the turnover among the four stressful life events. As to reality shock, the risk ratios of nurses who answered "occasionally" or "always" to those who answered "hardly ever" or "never", none of whom quit, were 7.47 and 7.95, respectively. Moreover, no significant difference in the turnover was evident between nurses who answered "always" and those who answered "hardly ever", "never" or "occasionally".

For ward assignment preference, the risk ratio of nurses who answered "dissatisfied to be assigned to a different ward" to those who answered "satisfied about being assigned to the ward of choice" was $2.95(p<.01)$. In terms of transfer preference, the risk ratios of nurses answering "want to change workplace" or "want to find another career" to those answering "no" were 2.93 and $2.79(p<.01$ and $p<.05)$, respectively. For job satisfaction, the risk ratios of nurses who answered "slightly dissatisfied" or "very dissatisfied"to those who answered "very satisfied" were 5.16 and $7.34(p<.05$ and $p<.01)$, respectively. No significant differences were evident with respect to salary, workload or overtime. The risk ratio of nurses without support from peers to those with support from peers was $2.45(p<.01)$. No significant differences were identified with respect to coping mechanism.

Multiple logistic regression analysis was conducted on variables with significant risk ratios, burnout scores with significant differences between nurses who quit and those who did not, gender and age. The stepwise method identified academic background, assignment, and support from peers as the factors affecting rapid turnover. The risk ratios of turnover were $6.29(p<.01)$ times greater for vocational nurses, $3.36(p<.01)$ times greater for those dissatisfied with their ward assignment, and $2.49(p<.01)$ times greater for those reporting a lack of social support from peers (Table 6).

Since the total MBI score and physical exhaustion score closely affected each other, variable selection was performed separately, but neither was selected. Assignment preference and social support from peers 
Table 6. Risk ratios and $95 \%$ confidence intervals for rapid turnover of novice nurses (multiple logistic regression analysis)

\begin{tabular}{lcc}
\hline & Risk ratio & 95\% CI \\
\hline Graduation from vocational nursing school & 6.29 & $2.19-18.06 * *$ \\
Dissatisfaction about being assigned to a different ward & 3.36 & $1.62-6.95 * *$ \\
Lack of social support from peers & 2.49 & $1.22-5.08 * *$ \\
\hline
\end{tabular}

$* *: p<0.01$

Table 7. Transfer preference with respect to final academic background

\begin{tabular}{|c|c|c|c|c|c|}
\hline & No & $\begin{array}{l}\text { Want to get a } \\
\text { higher degree }\end{array}$ & $\begin{array}{c}\text { Want to } \\
\text { change workplace }\end{array}$ & $\begin{array}{l}\text { Want to find } \\
\text { another career }\end{array}$ & Total \\
\hline \multicolumn{6}{|l|}{ Highest educational level } \\
\hline Vocational school of nursing & $306(60.0)$ & $58(11.4)$ & $103 \quad(20.2)$ & $43 \quad(8.4)$ & 510 \\
\hline College of nursing & $108(53.2)$ & $32(15.8)$ & $46 \quad(22.7)$ & $17 \quad(8.4)$ & 203 \\
\hline University of nursing & $97(55.4)$ & $23(13.1)$ & $25 \quad(14.3)$ & $30(17.1)$ & 175 \\
\hline $\begin{array}{l}\text { College or university degree } \\
\text { other than nursing }\end{array}$ & $11(52.4)$ & $3(14.3)$ & $3 \quad(14.3)$ & $4(19.1)$ & 21 \\
\hline
\end{tabular}

Table 8. Risk ratios and $95 \%$ confidence intervals for rapid turnover among novice nurses (only vocational nursing school graduates)

\begin{tabular}{|c|c|c|c|c|}
\hline & Frequency & Quit & Risk ratio & $95 \% \mathrm{CI}$ \\
\hline \multicolumn{5}{|l|}{ Transfer preference } \\
\hline No & 306 & 11 (3.6) & 1.00 & \\
\hline Want to get a higher degree & 58 & $6(10.3)$ & 2.88 & $1.11-7.47 *$ \\
\hline Want to change workplace & 103 & $11(10.7)$ & 2.97 & $1.33-6.65^{* *}$ \\
\hline Want to find another career & 43 & $3 \quad(7.0)$ & 1.94 & $0.56-6.68$ \\
\hline \multicolumn{5}{|l|}{ Ward assignment preference } \\
\hline Satisfied (the ward desired) & 248 & $10 \quad(4.0)$ & 1.00 & \\
\hline Satisfied (the ward not desired) & 178 & $9 \quad(5.1)$ & 1.25 & $0.52-3.02$ \\
\hline Dissatisfied (the ward not desired) & 82 & $12(14.6)$ & 3.63 & $1.63-8.09 * *$ \\
\hline \multicolumn{5}{|l|}{ Support from peers } \\
\hline Yes & 405 & $18 \quad(4.4)$ & 1.00 & \\
\hline No & 112 & $14(12.5)$ & 2.81 & $1.44-5.48 * *$ \\
\hline
\end{tabular}

$*: p<0.05, * *: p<0.01$

were selected even when academic background, gender and age were excluded.

Factors affecting rapid turnover and transfer preference among vocational nursing school graduates

ANOVA revealed that, for physical exhaustion, the nurses who quit had significantly higher scores than the nurses who did not $(p<.05)$, among only vocational nursing school graduates (data were not shown). Table 7 shows transfer preference with respect to final academic background. There were no significant differences; however, for transfer preference, vocational nursing school graduates had a tendency to have a higher proportion for "no" transfer preference and lower proportions for "want to get a higher degree" and "want to find another career" than the graduates with other final academic backgrounds. Table 8 shows the turnover, risk ratios, and $95 \%$ confidence intervals, for vocational nursing school graduates. There were significant differences among transfer preference, ward assignment 
Table 9. Risk ratios and 95\% confidence intervals for rapid turnover of novice nurses among only vocational nursing school graduates (multiple logistic regression analysis)

\begin{tabular}{lcc}
\hline & Risk ratio & 95\% CI \\
\hline Dissatisfaction about being assigned to a different ward & 3.56 & $1.63-7.75 * *$ \\
Lack of social support from peers & 3.17 & $1.49-6.74 * *$ \\
\hline
\end{tabular}

$* *: p<0.01$

Table 10. Nurse attributes and burnout and assertiveness scores with respect to social support from peers

\begin{tabular}{|c|c|c|c|}
\hline Support from peers & (yes, $n=722$ ) & $($ no, $n=201)$ & Total $(n=923)$ \\
\hline \multicolumn{4}{|l|}{ Gender } \\
\hline Male & $18 \quad(2.5)$ & $15 \quad(7.5)$ & $33 \quad(3.6) * *$ \\
\hline Location of the hospital in Tokyo & $348(48.2)$ & $78(38.8)$ & $426(46.2) *$ \\
\hline Living arrangements Living alone & $561(77.7)$ & $139(69.9)$ & $700(76.0) *$ \\
\hline \multicolumn{4}{|l|}{ Support from senior nursing staff } \\
\hline No & $448 \quad(62.1)$ & $179(89.1)$ & $627(67.9) * *$ \\
\hline \multicolumn{4}{|l|}{ Support from boss } \\
\hline No & $665(92.1)$ & $199(99.0)$ & $864(93.6) * *$ \\
\hline \multicolumn{4}{|l|}{ Burnout } \\
\hline Total MBI score & $12.0 \pm 2.3$ & $12.7 \pm 2.4$ & $12.2 \pm 2.3 * *$ \\
\hline Physical exhaustion & $3.6 \pm 1.1$ & $3.9 \pm 1.1$ & $3.7 \pm 1.1 * *$ \\
\hline Emotional exhaustion and depersonalization & $\mathrm{n} \quad 1.4 \pm 1.1$ & $1.7 \pm 1.1$ & $1.5 \pm 1.1 * *$ \\
\hline Personal accomplishment & $3.0 \pm 1.1$ & $2.8 \pm 1.1$ & $3.0 \pm 1.1 *$ \\
\hline Assertiveness & $-11.9 \pm 20.1$ & $-14.3 \pm 23.1$ & $-12.4 \pm 20.8$ \\
\hline
\end{tabular}

$*: p<0.05, * *: p<0.01$

preference and social support from peers as factors affecting rapid turnover. For transfer preference, the risk ratios of vocational nursing school graduates answering "want to get a higher degree" or "want to change workplace" to those answering "no" were 2.88 and 2.97 $(p<.05$ and $p<.01)$, respectively. When compared to the results for all subjects together, there was a significant difference for "want to get a higher degree" but not for "want to find another career". The stepwise method identified ward assignment preference and social support from peers as the factors affecting rapid turnover of novice nurses who graduated from vocational school (Table 9), as was also the case for all subjects together.

The characteristics of the novice nurses without support from peers

No significant differences were apparent with respect to age, final academic background, department and coping mechanisms between nurses without support from peers and those with support from peers.

Table 10 shows nurse attributes and burnout and assertiveness scores with respect to social support from peers. Novice nurses without support from peers had a significantly higher proportion of males $(p<.01)$, location of the hospital is not in Tokyo $(p<.05)$, living with family or inmate $(p<.05)$, and lack of social support from senior nursing staff and boss than those with support from peers $(p<.01)$. ANOVA revealed that the nurses without support from peers had significantly higher total MBI, physical exhaustion, and emotional exhaustion and depersonalization scores (respectively, $p<.01$ ), and lower personal accomplishment scores $(p<.05)$ than those with support from peers.

\section{Discussion}

The subjects of this study were single novice nurses without children who were working in university hospitals with more than 400 beds (excluding psychiatric hospitals) in Japan. Although the overall questionnaire response rate was as high as $85.6 \%$, response rates varied among the participating hospitals: $34 \%$ in one hospital, $50 \%$ in another and $60-100 \%$ in the remaining 18 . There were a few hospitals with $100 \%$ response rate. This may have occurred because these employed small numbers of nurses who may have felt compelled to answer by their superiors, who could easily monitor the number of answers. However, the novice nurses sealed the questionnaires envelopes and there were some blank questionnaires, 
suggesting that the freedom of choice of the nurses was assured.

If burnout and turnover had been high in the hospitals with low response rates, selection bias should have been taken into account. However, in fact, one of the hospitals with a low response rate reported no turnover. On the other hand, the hospitals with high response rates may have management systems under which subjects feel pressure. It might have influenced rapid turnover. The hospitals with $90 \%$ or more response rates indicated $4.48 \%$ turnover and the hospitals with lower than $90 \%$ response rates indicated turnover of $3.82 \%$. There was no significant difference between these two groups with respect to response rate. Moreover, there were no significant differences in the rates of turnover and invalid responses among the participating hospitals, in average scores on burnout subscales or in average assertiveness scores.

Students in Japan usually find employment in April. After being employed they receive semi-annual bonuses (in June and December) in addition to their salary. We assumed that the reason for quitting within twelve months was partly related to the time when the bonus was provided. Therefore, the 12th month after being employed was assumed to be a delimitation line for the study period. In this study, therefore, the novice nurse cohort at the 3rd month after being employed was assumed to be a baseline and the follow-up survey after nine months of employment was done, because we thought that clarifying the factors affecting rapid turnover would help to construct a system to support novice nurses.

The results of this study showed that graduation from a vocational nursing school, dissatisfaction about being assigned to a ward not of their choice and lack of peer support led to rapid turnover.

First, a comparison was made between the retirement factors of the nurses with much experience and those of the novice nurses. Regarding factors related to nurse turnover, age, job title, nursing experience, community satisfaction $^{2)}$, marital status ${ }^{2,11,12)}$, living together with a child $^{11)}$, moving ${ }^{12)}$, salary ${ }^{11-13)}$, burnout ${ }^{10,23)}$, job satisfaction $^{2,4,13,32)}$, hardness ${ }^{4)}$, interpersonal relationships with doctors, senior nursing staff and patients ${ }^{12,13)}$, organization commitment ${ }^{32)}$, and lumbar pain ${ }^{33)}$ have been reported. These factors differed from those affecting the rapid turnover of novice nurses in university hospitals.

Matsushita and Shibata ${ }^{34)}$ studied novice nurses $(\mathrm{n}=145)$ working in university hospitals in Tokyo and reported that the following factors were related to the turnover within the first three years: passive attitude in selecting nursing as a career, lifestyle inflexibility, assessment by supervisors; and guidance, advice, trust and expectations from senior nursing staff. Furthermore, Cowin ${ }^{35)}$ reported that veteran and novice nurses $(n=206)$ have different views on job satisfaction and turnover.
While veteran nurses gain job satisfaction through experience, and this satisfaction leads them to continue to work as nurses, novice nurses continue in nursing for financial reasons. In these studies, however, the numbers of novice nurses were small.

As for the burnout in this study, total MBI scores and physical exhaustion scores were significantly higher for the nurses who quit than for those who did not, but neither factor affected the rapid turnover of novice nurses when those scores were adjusted for confounding factors. Previous studies have identified burnout as one of the causes for nurses' turnover ${ }^{10)}$ and the degree of burnout is high among young nurses ${ }^{15,30,31)}$. However, burnout may not directly cause turnover among novice nurses. The results of this and previous studies suggest that different factors are involved in the turnover of experienced and novice nurses.

Duncan $^{36)}$ conducted a study on novice nurses $(n=63)$ who graduated from universities and emphasized the importance of the transitional period during which nursing students commence work and gain professional knowledge. In that study, the most important factor for novice nurses was the workplace atmosphere, and since this had the greatest influence on workplace commitment, the study concluded that it was very important to organize work environments and provide support to prevent rapid turnover.

Hayashi et al. ${ }^{37)}$ conducted an actual-condition survey on novice nurses $(\mathrm{n}=712)$ at national university hospitals $(n=42)$, and reported that $70 \%$ of nurses with less than one year of experience gave affirmative responses to the following five items regarding working relationships with their peers: "learn from each other", "exchange information", "help each other", "talk about personal matters", and "have friendships outside work". However, there is no viewpoint of burnout in these studies.

With regard to the social support, Matsushita ${ }^{34)}$, Duncan $^{36)}$ and Hayashi et al. ${ }^{37)}$ reported the importance of supervisors and seniors, the workplace atmosphere, and peers, respectively. The present study was a largescale, longitudinal one for novice nurses in university hospitals. We aimed to clarify the factors causing rapid turnover of novice nurses, and whether burnout affected factors related to the rapid turnover of novice nurses within the first nine months of starting nursing. The results of this study found that novice nurses who had no social support from peers were more likely to quit early. Almost $80 \%$ of the nurses reported having support from peers. However, we found that the proportion of nurses who reported discussing problems with their supervisors or senior nurses was low, presumably because this study was conducted within the first nine months of starting nursing. It is possible that novice nurses cannot form meaningful relationships with their supervisors and seniors within this transitional period. 
Oshita et al $^{38)}$ found that novice nurses $(\mathrm{n}=46)$ were most stressed about "performing life-saving work" and "dealing with difficulties of the job". When faced for the first time with being in a position of saving lives, novice nurses become isolated if they cannot exchange information with, learn from, or talk about personal matters with peers.

Moreover, this study showed that novice nurses who had no social support from peers were more likely to quit.

This type of isolation hastens resignation because nurses cannot find their role in the workplace. We believe that the presence of peers with whom novice nurses can talk and count on has an impact on rapid turnover. The results of this and previous studies suggest that lack of social support from peers affects turnover.

Features of the novice nurses without support of peers are male gender, hospitals outside Tokyo, living with family or inmate, and lack of support from senior nursing staff and boss. One reason for the lack of support from peers among male nurses might be attributed to a small number of male nurses in Japan. In the 3rd month after being employed, nurses who live alone in Tokyo might find it easier to form friendships with colleagues. In addition, nurses without support from peers might lack senior nurses and boss supports. Novice nurses without support from peers may burnout easily.

Of the above-mentioned three factors (final academic background, ward assignment preference, and social support), the last two are the easiest to address.

In other words, to lower turnover among novice nurses, it is best to assign novice nurses to the department of their choice as far as is possible, and to facilitate friendships among novice nurses within the first three months by holding group training and hosting recreational activities and trips. It is therefore best to avoid assigning only one novice nurse to a ward.

As to final academic background, at baseline vocational nursing school graduates had a tendency to show a higher ratio for "no", and lower ratios for "want to get a higher degree" and "want to find another career" than those with other final academic backgrounds with regard to transfer preference. They might have had higher motivation for nursing in their units than nurses with other final academic backgrounds. For the total group, the strength of their desire to obtain further higher education had no effect on rapid turnover. However, when limiting the subjects to vocational nursing school graduates, the strength of their desire to obtain further higher education had a significant effect on rapid turnover.

In university hospitals, which play a central role in advanced medical technology, the working nurses need to upgrade their skills. In such circumstances, the desire of vocational nursing school graduates to obtain further higher education may increase. Conversely, however, some may feel out of place in the highly specialized environment of the university hospital. Actually we have no idea whether vocational nursing school graduates who left their hospitals intending to obtain further higher education were able to realize this goal. However, for vocational nursing school graduates this desire is thought to be one of the factors affecting their rapid turnover. Further research is required to determine whether the novice nurses who left the hospitals continued with nursing work. The number of nursing universities with attached hospitals has increased in recent years. It seems that the employment of vocational nursing school graduates has decreased. However, nursing school graduates accounted for more than half of the subjects in this study. Though the number of nurses employed in hospitals is approaching the number recommended by the Ministry of Health, Labour and Welfare, the Four Hospital Group Conference ${ }^{39)}$ investigated 2,230 hospitals in 2004 and found about $50 \%$ of hospitals surveyed answered, "The number of nurses is insufficient". In view of such a result, hiring of vocational nursing school graduates is expected to continue in the future. In this study, it was clarified that the most significant factor for early turnover of novice nurses was having no adviser among their colleagues. Therefore, it is hoped that creating an especially strong system for the support of vocational nursing school graduates will decrease rapid turnover in the future.

It is necessary to conduct a longitudinal study in hospitals of other organizations and to develop concrete measures for training and support for novice nurses and assess the effectiveness of such intervention measures.

\section{Conclusions}

1. While mean scores for total MBI and physical exhaustion were significantly higher for the novice nurses who quit than for those who did not, it is considered that the direct effect of burnout on rapid turnover was low, based on the results of multiple logistic regression analysis.

2. In university hospitals, novice nurses who graduated from vocational nursing schools are more likely to quit early. One reason may be a desire for further education.

3. Novice nurses who are dissatisfied about not being assigned to their ward of choice are more likely to quit early.

4. Novice nurses who do not have peers to talk to and count on are more likely to quit early. The characteristics of the novice nurses without support from peers were male gender, hospitals outside Tokyo, living with family or inmate, lack of social support from senior nursing staff and boss. Novice nurses without support from peers may burnout easily.

Thus, to prevent rapid turnover, it is important to assign 
novice nurses to wards of their choice as far as is possible, to assign at least two novice nurses together to a ward, and to provide additional support for nurses who have graduated from vocational nursing schools.

Acknowledgments: We thank the novice nurses, directors and nursing department staffs for their help in the present study. This study was conducted as part of collaborative study with Kitaoka-Higashiguchi of Ishikawa Prefectural Nursing University, to whom we extent our gratitude for valuable advice.

This study was supported by a research grant from the Ministry of Education, Culture, Sports, Science and Technology of Japan in 2003-2005 (Number 15599343).

\section{References}

1) Japanese Nursing Association Survey and Research Section, Development and Promotion Department. Investigation of demand and supply for the hospital nursing stuff in 2002 (Issue Brief No.67). Tokyo: The investigation report of the Japanese Nursing Association, 2003: 19-33 (in Japanese).

2) S Pan, J Dunkin, KJ Muus, R Harris and JM Geller: A logit analysis of the likelihood of leaving rural settings for registered nurses. J Rural Health 11, 106-113(1995)

3) N Yoshida, I Toyomasu and S Kawaguchi: Mental health and related factors for the nurses retired in a short term after finding employment. J Occup Health 43, 499(2001) (in Japanese)

4) JH Larrabee, MA Janney, CL Ostrow, ML Withrow, GR Hobbs Jr and C Burant: Predicting registered nurse job satisfaction and intent to leave. J Nurs Adm 33, 271-283(2003)

5) W Ichikawa, R Sato and N Oozono: Literature review on research trend of novice nurse in Japan. Bull Fukushima Sch Nurs 5, 31-39(2003)

6) K Wakasa: The novice nurses under crisis. J Nurs Adm 9, 6-13 (1999) (in Japanese)

7) J Whitehead: Newly qualified staff nurses' perceptions of the role transition. Br J Nurs 10, 330-339(2001)

8) K Mori: The reality investigation of stresses which the new figure nurses employed after one month hold. Bull Fac Health Sci, Okayama Univ Med Sch 11, 71-76 (2001) (in Japanese with English abstract)

9) PR Messmer, SG Jones and BA Taylor: Enhancing knowledge and self-confidence of novice nurses: The "Shadow-A-Nurse" ICU program. Nurs Educ Perspect 25, 131-136(2004)

10) C Maslach, WB Schaufeli and MP Leiter: Job burnout. Annu Rev Psychol 52, 397-422 (2001)

11) CB Jones.: Registered nurse turnover and the changing health care system. Nursing Connections 9, 35-48 (1996)

12) M Shiomi, H Ooishi, T Tamai and M Yoshizaki: Report of reasons of resignation in nursing division. The Medical Journal of Sumitomo Hospital 26, 133-137 (1999) (in Japanese)

13) Y Nakayama and S Nojima: The factor analysis of job satisfaction and retention among nurses. Kango 53, 8191 (2001) (in Japanese)

14) EW McCranie, VA Lambert and CE Lambert Jr: Work stress, hardiness and burnout among hospital staff nurses. Nurs Res 36, 374-378 (1987)

15) T Yamazaki, M Ishida and E Kashiwakura: The relation between a tendency of burnout and social support among nurses: A comparative study of constituent members in two different hospitals. Bull Coll Med Sci, Tohoku Univ 8, 161-170 (1999) (in Japanese with English abstract)

16) T Kalliath and R Morris: Job satisfaction among nurses-a predictor of burnout levels-. J Nurs Adm 2, 648-654 (2002)

17) K Kitaoka-Higashiguchi and H Nakagawa: Job strain, coping, and burnout among Japanese nurses. Jpn J Health \& Human Ecology 69, 66-79 (2003) (in Japanese with English abstract)

18) MP Leiter and C Maslach: The impact of interpersonal environment on burnout and organizational commitment. J Organi Behavi 9, 297-308 (1988)

19) Health Policy Study Association, Ministry of Health Labour and Welfare. The Hospital Catalog 2001-2002. Tokyo: Igaku Shoin, 2000: 7-48 (in Japanese).

20) C Maslach and SE Jackson: The measurement of experienced burnout. J Occup Behav 2, 99-113 (1981)

21) K Higashiguchi, Y Morikawa, K Miura, M Nishijyo, M Tabata, K Yoshida, T Sagara and H Nakagawa: The development of the Japanese version of the Maslach Burnout inventory and the examination of the factor structure. Jpn J Hyg 53, 447-445 (1998) (in Japanese with English abstract)

22) E Suzuki, Y Kanoya, S Horii, E Takada, K KitaokaHigashiguchi and C Sato: The examination of practicality of the Japanese version of Maslach Burnout Inventory (MBI): Focusing on the rates replies, valid answers, and invalid answers among the replies. Journal of JSNR 27, 85-90 (2004) (in Japanese with English abstract)

23) NJ Lewiston, J Conley and J Blessing-Moore: Measurement of hypothetical burnout in cystic fibrosis caregivers. Acta Paediatr Scand 70, 935-939 (1981)

24) E Suzuki, Y Kanoya, S Ishida, T Katsuki and C Sato: The development of the Japanese version of the Rathus Assertiveness Schedule. Nihon Hoken Fukusi 10, 19 29 (2004) (in Japanese with English abstract)

25) E Suzuki, Y Kanoya, T Ktsuki and C Sato. Verification of the reliability and validity a Japanese version of the Rathus Assertiveness Schedule. In: Proceedings of JANS Fifth International Nursing Research Conference, Fukushima, 2004: 103.

26) S Rathus: A 30-item schedule for assessing assertive behavior. Behav Ther 4, 398-406 (1973)

27) TH Holmes and RH Rahe: The social readjustment rating scale. J Psychosom Res 11, 213-218 (1967)

28) Kramer M. Reality shock: why nurses leave nursing. California: Mosby, 1974: 1-8.

29) Pine A, Kafry D. Coping with burnout. In: Jones JW, ed. The burnout syndrome. Illinois: London House, 1982: 139-150. 
30) Y Futoyu: The relationship between nurse's job perception and burnout syndrome. J Kawasaki Med 23, 143-154 (1997) (in Japanese with English abstract).

31) E Suzuki, R Nagatsu and Y Morita: Burnout and assertion of nurses working in a university hospital. Nihon Hoken Fukusi 9, 11-18 (2003) (in Japanese with English abstract)

32) GL Ingersoll, T Olsan, J Drew-Cates, BC DeVinney and J Davies: Nurses' job satisfaction, organizational commitment, and career intent. J Nurs Adm 32, 250 263 (2002)

33) DA Stubbs, PW Buckle, MP Hudson, PM Rivers and D Baty: Backing out: Nurse wastage associated with back pain. Int J Nurs Stud 23, 325-336 (1986)

34) Y Matsushita and K Shibata: Factors in rapid turnover of nurses newly graduated from college: Motives of the selection of occupation and related factors half a year after employment. Bull Yamanashi Coll Nurs 6, 65-72 (2004) (in Japanese with English abstract)

35) L Cowin: The effects of nurses' job satisfaction on retention: an Australian perspective. J Nurs Adm 32, 283-291 (2002)

36) K Duncan: Student pre-entry experience and first year of employment. J Contin Educ Nurs 28, 223-230 (1997)

37) C Hayashi, M Ishii, T Iwabuchi, R Saitou, M Suematsu, Y Hattori and KYamaoka: Consideration and the realities of 712 novice nurses in the affiliated hospital of department of medicine at national universities Japanese. J Nurs Adm 9, 14-21 (1999) (in Japanese)

38) K Oshita, T Sasaki, C Murakami, K Hirata and K Hiraoka: Stressor surrounding novice nurses: studied with the load quantities in each stress factors and burnout scale. Sogo Kango 2, 16-21 (2001) (in Japanese)

39) Four Hospital Group Conference. Investigation on demand and supply for the nursing personnel. Tokyo: Four Hospital Group Conference, 2004: 11-13 (in Japanese). 